\title{
Un laboratorio politico-gremial: el sindicalismo revolucionario en la industria de la madera, 1915-1930
}

Walter L. Koppmann

FFyL - UBA

walter.koppmann@gmail.com

Al estudiar la intervención del sindicalismo revolucionario en el gremio de la madera de la ciudad de Buenos Aires durante el periodo 1915-1930 se presentan diversos interrogantes. La elección de este sector, donde la presencia de esta corriente fue muy destacada desde principios del siglo XX, no es casual. En primer lugar, la pregunta que guió nuestro análisis gira en torno a explicar por qué el gremio maderero fue una "piedra angular" de la construcción sindicalista en el movimiento obrero, entrelazando dimensiones tales como el proceso productivo, la organización en el lugar de trabajo y el rol de la militancia obrera. Desde esta perspectiva, su inserción en un gremio altamente calificado permitió matizar aquellas visiones que caracterizaban al sindicalismo como una corriente sólo presente en gremios industriales y en los grandes sindicatos del sector transporte y servicios, en contraste con los anarquistas, quienes lo habrian hecho en los gremios de oficio (Falcón, 1987; Suriano, 2001).

Un segundo conjunto de preguntas apuntaron a indagar por qué la intervención de los sindicalistas asumió una forma tan destacada en este sector y no en otros, y cuáles eran las formas organizativas así como las reivindicaciones que privilegiaban. En este punto, el análisis nos obligó a descentrar la mirada para explicitar su participación en la construcción de una central sindical nacional. Como veremos, dicha tarea no estuvo exenta de contradicciones y contribuyó a un proceso de diferenciación interna dentro de la corriente que, por lo general, suele ser soslayado en los análisis. En contraste, el gremio maderero resultó un laboratorio que concentró estas tendencias centrífugas.

Finalmente, la última parte del artículo reseña las tensiones originadas a partir de las distintas iniciativas estatales dentro del movimiento sindical, evaluando cuáles fueron las respuestas dadas desde el sin- 
dicalismo criollo. Antes que considerar el vínculo con el Estado como una conexión lineal e idéntica a sí misma en el tiempo, creemos que existieron modulaciones, aproximaciones sucesivas y distintos grados de integración, ya sea considerando a los distintos gremios como a la propia actuación de los militantes sindicalistas. Sería apresurado enfocar el estudio de esta corriente solamente desde una matriz institucionalista, que buscaría un diálogo pragmático y permanente (Caruso, 2016; Del Campo, 1983).

Nuestra investigación tomó como punto de partida el año 1915, cuando comenzaron a aparecer los primeros brotes de reactivación gremial, luego de años de desorganización y repliegue, que eclosionarian en junio del año siguiente en una huelga general maderera. La disponibilidad de un corpus documental de fuentes permitió dotar a esta investigación de un sustento empírico original. Así, un insumo clave provino del periódico gremial editado por el Sindicato de Obreros Ebanistas, Similares y Anexos. De igual manera, tuvimos en cuenta la publicación del Sindicato de Aserradores y Carpinteros de La Boca y Barracas, La Sierra (1920-1925). Además, analizamos los periódicos de las federaciones FORA IX y de su sucesora, la USA; prensas partidarias como La Vanguardia (periódico del Partido Socialista, PS) y La Internacional (órgano del Partido Comunista, $\mathrm{PC})$, entre otros materiales documentales.

\section{La organización de los trabajadores del mueble, el problema del oficio y el rol de los sindicalistas}

Desde principios del siglo XX, la actividad de la madera concentró a varios miles de trabajadores en el ámbito de una ciudad de Buenos Aires que se encontraba atravesando transformaciones de envergadura. A grandes rasgos, la industria argentina del mueble se configuraba como un crisol de pequeñas empresas individuales, con capital y personal muy reducidos y tecnología poco avanzada, comúnmente trabajando a un nivel casi artesanal, donde las normas laborales no estaban escritas y el sistema de control era de carácter familiar. Por sus dimensiones, a los talleres más pequeños se los llamaba "boliches" y constituían la mayoría dentro del sector, como ocurría también con otras ramas de la economía. En la ciudad de Buenos Aires, la producción mueblera se expandió con fuerza durante las décadas del 20 y 30, dispersándose en decenas de talleres (Camarero y Ceruso, 2015). En un principio, en los barrios de La Boca, Barracas, Parque Patricios y Pompeya; luego, Balvanera, San Nicolás y Almagro comenzaron a ser la sede de una gran cantidad de establecimientos. Desde los años 20, en Palermo, Villa Crespo, Paternal y, más tarde, Mataderos.

El hecho de que nuestra investigación haya gravitado fundamental- 
mente sobre el colectivo de los trabajadores ebanistas amerita explicitar ciertas características peculiares del oficio. La ebanistería se distinguía de la carpintería en que producía muebles más elaborados, generando nuevas técnicas; estas complejizaban el universo de oficios afines. De esta manera, existía una división gremial que abarcaba a lustradores, tapiceros, tupistas, maquinistas, doradores, silleteros y escultores. Sin embargo, al analizar la rama de la ebanistería en la ciudad de Buenos Aires hacia 1920, observamos que sólo unos pocos talleres tenian la capacidad de establecer una división del trabajo con funciones desagregadas en oficios parcializados, situándose en un punto intermedio entre la cooperación simple y la manufactura. En la mayoría de los casos, los boliches se caracterizaban por emplear un número mínimo de obreros sin mayor distinción de oficio, trabajando a un nivel artesanal y, por tanto, dependiente de la habilidad del obrero individual. En el plano de la estructuración sindical, los distintos gremios ("anexos") orbitaban alrededor del sindicato ebanista.

A la hora de vincular esta dimensión relativa al proceso de trabajo con las formas de organización sindical, hallamos de utilidad el concepto de "autonomía artesanal" (Montgomery, 1979), conceptualizando el "control obrero de la producción" no como un estado de cosas que existió en algún momento sino como una batalla crónica que asumió una variedad de formas, la primera de las cuales es la autonomía del artesano que aún no ha sido subyugado por la "gran industria" capitalista y que, por ende, habilita un cierto poder de resistencia frente a los deseos de sus empleadores. ${ }^{1}$

Sobre la trayectoria de su organización, los trabajadores de la industria maderera disponían de una gran tradición asociativa y las corrientes del movimiento obrero (socialistas, anarquistas y, sobre todo, sindicalistas) habian tenido una presencia significativa entre ellos desde principios del siglo XX. Por su parte, los comunistas comenzaron a tener una inserción molecular a partir de los años 1922-1923, si bien han aparecido indicios que dan cuenta de un cierto trabajo por parte de su organización antecesora, el Partido Socialista Internacional (PSI), entre los años 1918 y 1920, con la destacada actuación del obrero escultor Mateo Fossa. En términos generales, se trataba de una fracción de la clase obrera con un importante nivel de politización así como de organización sindical, ambos factores debidos probablemente al alto grado de calificación requerido en la labor y que se expresaba con nitidez en el caso del oficio ebanista. En particular, amerita ser destacado el carác-

1. La autonomía artesanal involucraba un "código de ética" que modelaba la conducta de estos trabajadores, los contornos que asumía la organización gremial y las formas de contralor obrero en el ámbito laboral (Montgomery, 1979: 14). 
ter activo y dinámico de este último gremio, con asambleas casi nunca menores al medio millar de asistentes y una alta tasa de sindicalización, logrando una notable incidencia en el movimiento obrero argentino desde sus orígenes. Podría afirmarse que, por su peso productivo y politico, el Sindicato de Ebanistas hegemonizaba la rama. Fue un "bastión" organizativo de los socialistas que pasó a manos sindicalistas, contando además con presencia anarquista y luego comunista.

Llegados a este punto de la exposición, es menester responder al primer interrogante: ¿por qué el gremio maderero apuntaló la construcción sindicalista en el movimiento obrero? Una buena parte de la respuesta a esta pregunta implicaría vincular las disposiciones subjetivas y el perfil de un obrero ebanista "promedio" con el ideario sindicalista y las prácticas militantes que rodearon la intervención de esta corriente en el sector del mueble, observando aquellas condiciones objetivas que enmarcaban el proceso laboral.

Así, suponemos una atmósfera de cierta respetabilidad dentro del universo de este sector de trabajadores, teniendo en cuenta que sus tareas abarcaban un mediano dominio del dibujo, cierto gusto estético $\mathrm{y}$, de conjunto, un necesario quantum de acervo cultural. De esta manera, el trabajo calificado resultaba el principal camino sobre el cual transcurría la organización, dentro un sector productivo escasamente desarrollado en términos capitalistas. En otras palabras, la "autonomía artesanal" dificultaba que los empleadores pudieran reemplazar fácilmente a los huelguistas, contratando otros obreros. Más aún, algunas crónicas narraban que los rompehuelgas terminaban arruinando los trabajos y las herramientas de los talleres. ${ }^{2}$

Por esta razón, para un ebanista no tenía demasiado sentido lanzarse a un movimiento general sin la adecuada preparación y cuyo final era incierto, resultando mucho más sencillo realizar huelgas parciales. En este gremio, la declaración de la huelga general se emparentaba con un argumento de carácter político, frecuentemente esgrimido desde los sectores anarquistas. Quienes percibieron con mayor claridad este elemento peculiar fueron primero los socialistas (circa 1897, en la figura de Carlos Mauli) y luego, con mayor fuerza, los sindicalistas, destacándose importantes cuadros, como Juan Cuomo, Juan Perazzo, Ángel Renoldi, entre otros. En el caso de esta corriente podriamos afirmar que hicieron de la "autonomía artesanal" un verdadero "talismán" de la organización sindical.

En una segunda operación analítica, resulta necesario contestar: ¿por qué la intervención de los sindicalistas fue tan destacada en este sector y no en otros? En términos concretos, ¿qué expresiones asumía

2. "En la casa Waring y Gillow", La Vanguardia, 20 de octubre de 1915. 
la concepción sindicalista acerca de la "capacitación progresiva de la clase obrera" en la industria del mueble o en qué medida la configuración de esta última tornaba realizable el planteo teórico del "embrión"? ${ }^{3}$

Desde la visión sindicalista, el "dominio" del taller acrecentaba la "moral revolucionaria" de la clase productora, cuya capacitación progresiva sobre el proceso de trabajo tendía hacia la dirección total de la sociedad capitalista. Así, su repertorio organizacional ${ }^{4}$ se hilvanaba con la búsqueda por generar cierto contralor obrero dentro de los talleres, en tanto práctica que prefiguraba la futura dirección de una sociedad de productores libremente asociados. El principal elemento que facilitaba la organización en los establecimientos madereros controlados por los sindicalistas era la tarjeta sindical, que validaba la afiliación al gremio y sin la cual los obreros no podian ingresar a trabajar a los talleres sindicalizados. Muchos se referían a la imposición de esta credencial como una suerte de "control obrero": "La tarjeta es una conquista netamente obrera que solamente los obreros que son capaces y están organizados la pueden imponer dentro del taller capitalista. Es el control de la organización, que tienen los obreros conscientes". ${ }^{5}$ En la misma dirección se representaba la jornada laboral de 44 horas que "impuesta por el sindicato es signo de su poder y da la pauta del control obrero de la producción". ${ }^{6}$ En sí, el problema de la "capacitación de la clase obrera" representaba uno de los núcleos esenciales del pensamiento sindicalista revolucionario (Bilsky, 2011).

Como es de imaginar, sostener esta clase de conquistas requería de una sólida estructuración sindical cuya condición era el delegado en los lugares de trabajo. Este representaba a los trabajadores frente a la patronal y los ligaba al sindicato, garantizando la distribución del periódico gremial y la rendición de las cotizaciones (en muchos casos, se exigía como parte del "reconocimiento sindical" el ingreso del cobrador al taller). El delegado podía ser votado por sus compañeros de trabajo o nombrado por la conducción del sindicato. Durante los años 20, momento de descenso de las luchas y de la organización gremial, la desvinculación del delegado permitió vulnerar la jornada de 44 hs. y

3. La palabra "embrión" se utiliza para dar cuenta de que, al interior de la fábrica y en la lucha de los obreros por la dirección del proceso productivo, se alojaba el embrión de la sociedad futura. "La revolución obrera", El Obrero Ebanista, n 94, julio de 1920.

4. Hallamos de utilidad el concepto de "repertorio organizacional", operativizado por Camarero (2007) y Ceruso (2015) para dar cuenta de aquellas modulaciones tácticas que se derivaban de las estrategias adoptadas por cada una de las corrientes. Cabe remarcar la cercanía de esta categoría con el concepto de "repertorios de la acción colectiva" (repertoire of collective action), elaborado por Charles Tilly (1995).

5. "La tarjeta sindical”, El Obrero Ebanista, n 81, marzo de 1918.

6. "El acortamiento de la jornada de trabajo", ídem. 
restablecer el sistema de trabajo a destajo, dos elementos claves para maximizar la tasa de ganancia empresarial. La figura del delegado, por último, facilitaba las reuniones de personales con la conducción sindical.

Dentro del sector, la corriente sindicalista impulsó luchas que apuntaban a obtener distintas reivindicaciones gremiales, entre otras: provisión de herramientas y banco a cargo de la patronal; viáticos para aquellos obreros que realizaban trabajos en obras e instalaciones fuera del taller; seguro por accidentes de trabajo desde el momento en que este se produjera; abolición del trabajo a destajo, de la jornada dominical y de las horas extras; reconocimiento sindical para garantizar todos estos elementos. ${ }^{7}$

En este punto, creemos que si en algún sector productivo tenía posibilidades de prevalecer esta perspectiva de "capacitación progresiva de la clase" era en la industria del mueble. La dispersión geográfica de los establecimientos, la mayoría de ellos "boliches" con baja densidad de empleados; el carácter artesanal de la actividad; las frecuentes penalizaciones pecuniarias a los patrones por entenderlos como "causantes" de los conflictos; la tarjeta sindical (e incluso, cierto dominio sobre el producto del trabajo, como sucedía con el "label"); ${ }^{8}$ todos estos elementos, que formaban parte de la vida cotidiana de los obreros, pueden ser considerados como factores que contribuyeron a darle un cariz de realidad a la praxis pregonada por los sindicalistas.

En definitiva, podemos afirmar que uno de los supuestos sobre los cuales reposaba la acción de esta corriente era la alta calificación de la mano de obra ebanista ("autonomía artesanal") y, en un grado no menor, el nivel de ocupación dentro de la industria. Por lo tanto, si el desempleo representaba a todas luces un punto de debilidad en momentos de recesión económica, en cambio, cuando el ciclo se revertía y abundaba el trabajo, los obreros madereros (y, en especial, los ebanistas) contaban con un "arma" muy poderosa a la hora de entablar la lucha contra los capitalistas. Durante la temporada alta de trabajo, los sindicalistas impulsaban las luchas parciales y ocupaban a los huelguistas en otras casas "en condiciones" o les abonaban un subsidio. De hecho, la dirección sindicalista congratulaba especialmente a los trabajadores que lograban sus aspiraciones sólo a través del "petitorio" y de la organización del personal: "Una vez que han comprobado los obreros el poder que ellos tienen [...] no tienen necesidad de ir a la huelga". ${ }^{9}$

7. "Historia del Sindicato de Ebanistas", El Obrero Ebanista, n 94, julio de 1920.

8. El "label" era una vieja técnica que consistía en imprimirle una marca al producto para dar cuenta de que había sido producido por obreros sindicalizados. "El label sindical", El Obrero del Mueble, n 8, diciembre de 1924.

9. "Movimiento sindical", El Obrero Ebanista, n 86, marzo de 1919. 
Hacia el año 1920, dado el alcance y la extensión de la "tarjeta sindical" en una gran cantidad de talleres, una táctica empleada por las patronales para quebrar la huelga y violentar la organización obrera en los lugares de trabajo fueron los llamados "dividendos", "cooperativas" o "centuriones", que eran distintas formas de contar con obreros "libres" a su disposición (Ceruso, 2015) $\cdot{ }^{10}$ Llegado a un extremo, el sindicato conseguía generalmente que el capitalista cediera a sus reclamos ya que, de lo contrario, no contaba con la fuerza de trabajo necesaria para la producción. Así, el Sindicato de Ebanistas tenía el poder (hasta cierto punto) de quebrar económicamente a los "bolicheros", bloqueándoles el acceso de personal capacitado. Además, en época de suspensiones, el sindicato proponía el establecimiento de turnos de trabajo.

A la postre, el contralor obrero sobre la contratación de la fuerza de trabajo derivó en una alta tasa de sindicalización. Según las fuentes consultadas, las cotizaciones anuales al Sindicato de Ebanistas pasaron del mínimo histórico de 2.000 en 1915, a 4.000 en 1916, 7.000 en 1917, 17.000 en 1918 y, finalmente, 33.800, en $1919 .{ }^{11}$ En síntesis, planteamos que existió una vinculación directa entre el aumento o la disminución del empleo, la "autonomía artesanal" derivada de la configuración del proceso de trabajo y la extensión o atrofia de la organización sindical. Es sobre este tripode donde pivoteaba la estrategia sindicalista.

De esta manera, puede describirse a grandes rasgos su trayectoria, tendiente a la consecución de reivindicaciones parciales mediante el método de la estructuración sindical del personal y la votación de delegados en los lugares de trabajo como paso previo para afrontar las luchas, dirigidas a conseguir mejores condiciones de explotación de la fuerza de trabajo, ya sea en el plano de la explotación material de la misma, es decir, como fuente de valorización del capital; ya sea en el plano del mercado, esto es, en tanto valor de cambio o valor, equivalente a una determinada cantidad de dinero (el salario del obrero). Asimismo, cabe añadir que, por lo general, la negociación con las patronales se realizaba a través de una comisión integrada por miembros de la Comisión Administrativa (CA) del sindicato y no de un comité de huelga del establecimiento; en repetidas ocasiones, incluso en el marco de un conflicto laboral. Por lo tanto, podemos avanzar señalando que la estrategia sindicalista combinaba un momento de descentralización, mediante la organización de los lugares de trabajo vía delegados, con otro de fuerte

10. "Dividendo, cooperativa o centurión. Necesidad de combatirlo", El Obrero Ebanista, n 89 , noviembre de 1919.

11. Como señala Lobato (2000), se trata de cifras especulativas en un momento cualitativamente diferente del nivel de sindicalización alcanzado más tarde, cuando se tornó obligatorio. "Historia del Sindicato de Ebanistas", El Obrero Ebanista, n ${ }^{\circ}$ 94, julio de 1920 . 
centralización, a través de la intercesión directa de la conducción del sindicato frente a los patrones, sustituyendo al personal en huelga.

Es factible afirmar que la dirección sindical era en parte consciente de esta orientación; en ocasión de la masacre de la llamada Semana Trágica de enero 1919, señalaba: "Hemos presenciado también, ¿por qué no decirlo? la tenaz persecución policial contra nuestros hermanos de la FORA V mientras intencionalmente se nos toleraba a nosotros una relativa libertad". ${ }^{12}$ Dos meses más tarde, Juan Cuomo defendia su postura, sosteniendo que: "Se nos mira como obreros que no luchamos sino solamente por el aumento de salarios, y que no somos un sindicato revolucionario [...] Hemos hecho y seguimos haciendo huelgas parciales por dignidad y respeto". ${ }^{13} \mathrm{Al}$ año siguiente (1920), se ratificaban las ventajas de los movimientos parciales:

Sin condenar los movimientos generales, simultáneos, parécenos conveniente el sistema de lucha que se viene practicando. Este sistema tiene, sobre las acciones simultáneas, la ventaja de no comprometer jamás el triunfo que se persigue. Un personal en huelga, siendo un poco diligente, puede fácilmente triunfar; y en una circunstancia adversa, puede contar con la solidaridad del resto del sindicato para llevarlo al triunfo. Esa solidaridad, al ser prestada por elemento que trabaja, puede significarse por hechos que serian imposibles cuando la huelga es general. ${ }^{14}$

Situados en esta instancia del análisis, surge la siguiente inquietud: ¿por qué la dirección política del proceso de estructuración sindical de los obreros muebleros durante prácticamente las tres primeras décadas del siglo se identificó con la corriente del sindicalismo revolucionario y no, por ejemplo, con los socialistas, quienes habian tenido una presencia mayoritaria en este colectivo de trabajadores desde sus orígenes? Más aún, cabe la comparación entre la orientación de los obreros socialistas en la industria aserradora y hacia el interior del gremio ebanista: mientras que en la primera boicoteaban las medidas de lucha "sin limite" convocadas desde el anarquismo, dentro del Sindicato de Ebanistas elogiaban la preparación, la deliberación consciente, la solidaridad colectiva y el grado de combatividad, en una suerte de "modelo" a seguir. Los términos en los cuales se expresaban estas ideas solían ser bastante similares a los empleados por los sindicalistas:

12. "Por la unificación obrera", El Obrero Ebanista, marzo de 1919.

13. "No se nos comprende", El Obrero Ebanista, n 86, marzo de 1919.

14. "Informe general de Secretaría. Consecuencias del triunfo de febrero", El Obrero Ebanista, no 94, julio de 1920. 
Este sindicato es uno de los que marchan a la vanguardia del movimiento obrero, por haber seguido siempre por un sendero razonable y práctico. En todos los movimientos que ha sostenido, ya sea al reclamar mejores condiciones de vida o ya al levantarse entusiasta para defender los derechos de organización amenazados, nunca ha dado una nota ingrata, sino que ha sabido defenderse de la clase patronal dentro de un terreno culto e inflexible. ${ }^{15}$

De todas formas, la declaración de la huelga general probó ser "eficaz" en un contexto ofensivo como el del año 1919, cuando los anarquistas avanzaron en la reconstrucción de la Federación de Trabajadores en Madera (FTM), de la que los ebanistas se habian separado a comienzos de 1918. Así, el 30 de febrero de 1919 se declaró por constituida la "Federación Regional de Trabajadores en Madera". ${ }^{16}$ El hecho de que los dos revisores de cuentas fueran de los gremios de carpinteros y constructores de carros remataba la hegemonia anarquista. ${ }^{17}$ Hacia la mitad de 1919, el debate se reabrió en el seno del sindicato ebanista y finalmente, la CA sindicalista se vio obligada a adherir a la FTM, nombrando como delegados a José Angeliollo y Roque Pugliese. ${ }^{18}$ En octubre de 1920, la FTM declaraba agrupar 26 sindicatos, "adheridos a ambas federaciones (del V y del X congreso)". ${ }^{19}$

Resta precisar, entonces, por qué el sindicalismo tuvo un dominio mayor que los socialistas. Después de todo, varias de las características del gremio se emparentaban con la "mirada civilizatoria" del PS sobre la lucha de clases: a) un sector compuesto sobre todo por oficiales calificados, con una sólida tradición asociativa y en la cual los anarquistas tenian baja influencia; b) donde las huelgas solían ser bien preparadas y los trabajadores actuaban en forma homogénea, sin ofrecer flancos a los empresarios, manteniendo el "orden" en las asambleas y evitando las discusiones promovidas por los anarquistas; c) por lo general, los

15. "Sindicato de Obreros Ebanistas, Similares y Anexos", La Vanguardia, 26 de julio de 1920.

16. La componian las siguientes sociedades: Carpinteros y Aserradores de Palermo, Aserradores y anexos de B. y Barracas, Torneros en Madera, Constructores de carros, Galponistas y Escaleristas, Bauleros y Valijeros, Talleres rurales unidos, Carpinteros de ribera, Carpinteros sobre flota, Aserraderos y Anexos de San Fernando, Tigre e islas y Aserradores de Avellaneda. La secretaría quedó instalada en la calle México 1824. "Federación de Trabajadores en Madera", La Vanguardia, 14 de marzo de 1919.

17. "Federación de Trabajadores en Madera", La Vanguardia, 9 de septiembre de 1919. 18. “Asamblea ordinaria”, El Obrero Ebanista, no 88, agosto de 1919.

19. "Federación Obrera de Trabajadores en Madera", La Vanguardia, 29 de octubre de 1920. 
reclamos incluían los puntos fundamentales del programa mínimo en su parte económica: no se limitaba al aumento de salarios sino que exigía la supresión del trabajo a destajo y la reducción de la jornada laboral; d) la coincidencia en el método propuesto por los sindicalistas de concentrar la fuerza de forma parcial, evitando la huelga general. ${ }^{20}$ Aunque dificil de medir, el ascendiente del PS entre estos trabajadores fue relevante (véase el espacio dedicado al gremio en La Vanguardia), si bien su implantación no fue mucho más allá de algunas figuras individuales (como la de Israel Landan entre los obreros judíos o Luis Fernández entre los escultores), opacada por la intensa actividad sindicalista. Resalta, en cambio, la escisión entre acción gremial y acción política y, por lo tanto, el hecho de que el socialismo haya resultado mucho más relevante como empresa política, social, cultural y en parte intelectual, pero intrascendente como expresión orgánica de la clase obrera (Camarero y Herrera, 2005).

\section{El Sindicato de Ebanistas y la construcción de una central obrera nacional}

Al estudiar al sindicalismo criollo, un aspecto poco atendido ha sido el vínculo entre la militancia de base y la construcción de las federaciones nacionales (FORA IX, primero, y la USA, después). En este plano, la pregunta podría resumirse en los siguientes términos: ¿en qué medida se valian los sindicalistas de su intervención al frente de ciertos gremios para construir una central obrera nacional? Una primera aproximación al problema permite constatar la función de "cantera" de cuadros políticos que cumplía el sector maderero, apareciendo un conjunto de militantes obreros que se destacaron durante largos períodos como constructores de una estructuración sindical nacional. Entre otros, cabe citar especialmente a Alejandro Silvetti y a Juan Cuomo.

De pasado anarquista y múltiples nombres, expulsado de Brasil y Uruguay por sus actividades politicas, Silvetti resaltaba por su pragmatismo y por la capacidad para expresar sus ideas y posiciones en términos asequibles para cualquier trabajador. ${ }^{21}$ Lejos del ideal de un obrero con dotes intelectuales y gran oratoria, Silvetti era un militante con años de experiencia (fundó cantidad de periódicos y protagonizó la creación de la Federación Maderera en Uruguay). En términos políticos, Alejandro Alba (uno de sus tantos nombres) pasó del apoyo inicial al

20. Para construir esta respuesta, consideramos varios de los puntos mencionados por Poy (2014).

21. Para una descripción más pormenorizada sobre la trayectoria de Alejandro Silvetti, véase Troncoso (1983). 
proceso revolucionario ruso (siendo uno de los redactores del periódico ácrata prosoviético Bandera Roja), a inclinarse, a mediados de 1922, del lado de los sindicalistas "autonomistas", esto es, favorables a la "neutralidad sindical" frente a los partidos políticos y, sobre todo, frente a la Internacional Comunista y la Internacional Sindical Roja (ISR). Representante de toda una generación de militantes obreros, Silvetti fue uno de los principales impulsores de la fundación de la Confederación General del Trabajo (CGT), en septiembre de 1930, en el contexto de una orientación determinada por la búsqueda de un interlocutor desde el lado estatal, aún en el marco de una dictadura con características fascistoides como la del general Uriburu.

El caso de Cuomo es menos conocido aunque no por ello menos relevante para el análisis. Alistado en la Unión General de los Trabajadores (UGT) desde sus comienzos, fue electo varias veces secretario general del sindicato ebanista. Posteriormente dentro de la Confederación Obrera de la República Argentina (CORA), representó a esta entidad durante la huelga de la Unión de Canteras en 1910 y en múltiples ocasiones fue delegado para "jiras" así como para tareas de primer orden en la organización de la vida interna de la federación (como, por ejemplo, llevar la solidaridad obrera y un aporte de $\$ 1000$ durante la huelga general maderera de Montevideo, en agosto de 1919). Hecho significativo, en 1919, fue parte de la comitiva que se entrevistó con Yrigoyen a la salida de la Semana Trágica; además, presidió la comisión de poderes del congreso de la FORA IX en febrero de 1921 e integró el comité mixto de junio de 1921 para liberar a los presos de la huelga general (Marotta: 1970). Dentro del gremio ebanista, fue uno de los principales portavoces de las posiciones "oficiales" del sector sindicalista "autonomista", merced a la autoridad que le brindaba su destacada actuación durante años.

En cierto modo, tanto Cuomo como Silvetti personifican todo un estilo de dirigencia sindical que combinaba un pragmatismo de carácter reformista con una orientación tendiente a la vinculación con el Estado y el poder político (Del Campo, 1983). De alguna manera, la fisonomía de este sector cristalizaria con mayor claridad en el contexto del declive huelguístico y organizativo de los 20 y a través de los debates con los sindicalistas "rojos", que comentaremos en el próximo apartado. Algunos de los referentes del sector sindicalista "ortodoxo" fueron Pascual Plescia, Pedro Alegría, Ángel Renoldi, Juan Roselló, Adán Ibañez, José Angeolillo, José Montesano, entre otros. El peso de los sindicalistas dentro del gremio ebanista, por otra parte, fue decisivo para terciar dentro del movimiento general; a modo de muestra, en el Congreso de Concentración, convocado por la CORA en 1914, de siete miembros componentes de la mesa directiva, tres eran ebanistas y militantes de 
la corriente del sindicalismo revolucionario: Juan Cuomo, el escultor Juan Perazzo y Ángel Renoldi (Marotta, 1961).

Podemos avanzar en que la gravitación de los sindicalistas sobre el gremio maderero fue una de las condiciones de posibilidad para la edificación de una central obrera nacional, valiéndose de cuadros militantes con años de trabajo gremial y, en un mismo plano de importancia, con un sólido dominio sobre un sindicato reputado en la época por su consistencia organizativa, incluyendo el aspecto financiero. En el terreno de la construcción de la sucesora de la FORA IX, la USA, cabe afirmar que la experiencia fue bastante similar.

De forma general, el período que va de 1921 a 1923 abarca años de poca actividad y de crisis dentro de la industria maderera, con una extensión de los desempleados y la consiguiente desorganización de los trabajadores. Si bien la impronta sindicalista en el gremio ebanista se mantuvo prácticamente durante toda la década del 20, el cambio en la relación de fuerzas con los patrones (a posteriori de la fallida huelga general de 1921) y cierto reflujo en el activismo obrero de la época determinaron un declive de la estructuración sindical. El repliegue en los lugares de trabajo conllevó una vuelta hacia atrás de los derechos y obligaciones contraídos con los dueños de los talleres, arrancados en el período de alza huelguística de 1917-1920. Esto implicó una ruptura de los vasos comunicantes entre la dirección de la CA sindicalista y los lugares de trabajo, a lo cual contribuyó la falta de control sobre las condiciones laborales (jornada, salarios, contratación, entre otros) e, indudablemente, la "ausencia de participación" por parte de los propios trabajadores. En forma sintética, aunque la falta de huelgas y la disolución de los organismos sindicales no fueron tan amplias como en general suele catalogarse, se puede afirmar que la ofensiva patronal posterior a 1921 logró desarticular -al menos temporalmente- los resortes de control obrero, desorganizando los talleres madereros.

No obstante, los sindicalistas afianzaron una sólida posición dentro de la USA, favorecidos por el peso relativo que tenía el Sindicato de Obreros de la Industria del Mueble, fundado a fines de 1923 como la unión de los distintos oficios bajo la égida del gremio ebanista, en un marco general de declive de la actividad sindical de los otros sectores $\mathrm{y}$, en particular, en términos de afiliados. Esto se debía a que, si bien el sindicato del mueble había decrecido en cotizantes (oscilando en 1926 entre 1.790 y 2.800 ), era el "sindicato numéricamente más importante" frente a la exigua organización que presentaba el movimiento obrero en aquel momento. ${ }^{22}$ Entre otros motivos, este factor explica por qué los militantes sindicalistas del mueble se habian opuesto al llamado al

22. "E1 miedo a los sindicatos grandes", Acción Obrera, n 23, mayo de 1926. 
congreso ordinario de la USA de $1926 .{ }^{23}$ Dicho congreso presentó un decrecimiento respecto al pasado tanto en el número de sindicatos afiliados como de cotizantes, contando con la presencia de 101 sindicatos que agrupaban, en su totalidad, 16.156 trabajadores (Marotta, 1970: 206). En aquel momento, la Confederación Obrera Argentina (COA), influenciada por el PS, contaba con casi 90.000 afiliados, gracias al peso de los ferroviarios. ${ }^{24} \mathrm{~A}$ continuación, dedicaremos un apartado a examinar el proceso de diferenciación interna que ocurrió por estos años en el seno de la corriente sindicalista.

\section{Sindicalistas "rojos" y sindicalistas "autonomistas"}

A comienzos de la década del 20 , en un contexto de retracción de las luchas y de la organización obrera, comenzó un proceso de diferenciación hacia el interior de la corriente sindicalista, acicateado por la estabilización de la Revolución rusa. Así, el debate sobre si apoyar o no el proceso soviético, en primer lugar, y, en segundo término, respecto a si adherir o no a una organización internacional de trabajadores, delimitó los campos más allá de las identificaciones de "políticos" y "antipolíticos", dado un fenómeno revolucionario ajeno a los cánones reconocidos. De esta forma, la iniciativa bolchevique por constituir la ISR volvió a colocar "el problema de las internacionales". Este factor catalizó la emergencia de un nuevo centro de irradiación doctrinal y organizativo (Aquino, 2015). Según el autor, existen pistas que afirmarian la existencia de un pequeño núcleo de sindicalistas que se adueñó de varias de las ideas y prácticas de los "maximalistas rusos". Dentro del grupo, las opiniones eran heterogéneas; tampoco está claro cuáles fueron sus dimensiones ni su incidencia en el movimiento obrero de la época. De cualquier manera, podemos distinguir una tensión básica entre la aceptación de la dictadura del proletariado y la denostación del partido revolucionario, por un lado, y la teoría del sindicato como "embrión", por el otro ("todo el poder a los sindicatos").

Los sindicalistas que se orientaban por una "finalidad revolucionaria", a través de los planteos de "agrupaciones sindicales" o de "federación sindicalista" se diferenciaban de aquellos que luchaban "exclusivamente por el salario". El debate apuntaba a los fundadores de la FORA IX,

23. "Un acuerdo equivocado", Acción Obrera, n 20, enero de 1926.

24. La preeminencia sindicalista en la USA afianzó su sectarismo excluyente ("antipolítico") y posibilitó la expulsión de los comunistas Rúgilo y Cantor. En octubre de 1927, el comunista Salomón Elguer corrió la misma suerte. "Se excluyeron dos miembros del Comité de la USA", Acción Obrera, n 25, julio de 1926; "El por qué de mi expulsión del CC de la USA", La Internacional, 8 de octubre de 1927. 
acusándolos de deformar la esencia del sindicalismo y se los nombraba como "amsterdamianos" o "amarillos". La generación de activistas etiquetados bajo esta denominación abarcaba a individuos que habían liderado la organización en momentos clave: en las luchas obreras de la primera década del siglo, en las revueltas sociales durante el Centenario y en el más reciente ciclo de huelgas, 1916-1921. Según los detractores, este sector incluía a "Los elementos que ejercen hegemonía en el actual Consejo Federal de la FORA y su órgano oficial, en el Sindicato de Ebanistas, en el consejo de la F.O. Local, en la Confraternidad Ferroviaria, en la F.O. Marítima y algunas otras organizaciones". ${ }^{25}$

La responsabilidad principal se adjudicó a una supuesta burocratización de las mayores organizaciones gremiales a partir de la confluencia de tres elementos. Un primer factor se referia a que el sindicato había pasado a tener un valor en sí mismo, debilitándolo como medio de lucha. Los sindicalistas críticos afirmaban que "la acción sindical [...] se concreta a tener registros de socios escrupulosamente llevados a reunir la mayor cantidad posible de cotizantes, a presentar los balances que arrojen saldos de muchos pesos" ${ }^{26}$ En el gremio maderero, el desarrollo del aparato reposaba en el control del personal (vía la "tarjeta sindical") y se reflejaba en una obstinada defensa de carácter corporativa, base del enfrentamiento crónico entre carpinteros y ebanistas.

En segundo lugar, aparecía el tópico sobre los cargos "rentados" en los sindicatos, un debate frecuente en estos años. Para los "reformistas", los rentados no eran un problema de doctrina sino de necesidad "y esto podría ser objeto de censura sólo en el caso de que se invirtieran en cargos rentados, mayor cantidad de dinero de lo que en realidad es necesario". De modo tal que "la remuneración a los empleados que se encuentran a su servicio [de la organización obrera] debe fijarse de acuerdo con el salario que estos perciban en el ejercicio de sus respectivos oficios". ${ }^{27}$ Los sindicalistas defendian las rentas como una función que habian adoptado "las organizaciones importantes que congregan en su seno un gran número de trabajadores", frente al "eterno estribillo de que los trabajos de la organización deben quedar librados a la buena voluntad de los militantes, sin estipendiarlos". ${ }^{28}$ Desde la óptica de los sindicalistas "rojos", la apreciación sobre la "burocracia" apuntaba a que muchos de sus líderes se habian apoltronado en sus organizaciones, alejados de las luchas cotidianas y volviéndose una casta incontrolada.

Si bien han sido profusos los debates sobre si es factible enunciar

25. “¿Sindicalismo?”, La Batalla Sindicalista, 6 de marzo de 1922.

26. Ibídem.

27. "La burocracia sindical", El Obrero Ebanista, n 113, julio de 1922.

28. Ibídem. 
la existencia en los años 20 de una "burocracia sindical", no dejaban de existir maniobras arbitrarias y particularistas entre algunos de los dirigentes sindicales. Por ejemplo, en 1919 se dio un curioso episodio en el gremio ebanista cuando un obrero de apellido "Gómez", ligado al PS, denunció en varias asambleas distintos manejos por parte del sector dirigente del sindicato: acomodamiento de militantes y obreros afines en talleres clave; utilización discrecional de los fondos sindicales para sostener rentas militantes; el recurso de las armas (generalizado en la época) y las "apretadas" a los disidentes..$^{29}$ Frente a esta denuncia, una asamblea votó exigir explicaciones a la conducción sindical. No obstante, Gómez acabó siendo expulsado del sindicato por "calumniador" y "falsificador". 30

El último punto de las críticas de los "rojos" fue el acercamiento a las instituciones burguesas y la tendencia a encauzar la conflictividad obrera hacia la esfera estatal. Bajo la envoltura discursiva de una "unidad" que aglutinara a los trabajadores en tanto clase explotada por el capital y con una retórica obrerista y antiestatista, los sindicalistas desenvolvieron una realpolitik pragmática, en relación al aparato estatal y el poder político, y sectaria y "exclusivista" en el seno del movimiento obrero. En el gremio, algunos representantes del sindicalismo "rojo" eran el destacado cuadro Aurelio Hernández, y otros como Eduardo Carugatti, José Morales, Vicente Tidone, Julio Cruces, Emilio Mársico, entre los más visibles. A mediados de 1925 , muchos se pasarian a las filas del comunismo.

\section{Vinculación con el Estado, legislación y derechos laborales: ¿cooptación desde arriba o integración desde abajo?}

Como vimos, el sindicalismo hizo de su intervención en el gremio del mueble una suerte de "modelo a seguir", apoyándose en su carácter activo y su alta tasa de sindicalización (lo cual implicaba un financiamiento importante) con el objetivo de apuntalar la estructuración de las centrales nacionales. Sin embargo, los años posteriores a la huelga general de junio de 1921 evidenciaron el retroceso parcial de la organización en los lugares de trabajo, a raíz del despido de delegados y activistas, y la merma en la participación de los trabajadores. Estos factores acabaron por anular el momento "descentralizado" entre el taller y la conducción

29. "En el seno de los gremios. Sucesos desagradables", La Vanguardia, 30 de marzo de 1919.

30. "Sociedad de obreros ebanistas. Resolución de un asunto interno", La Vanguardia, 15 de mayo de 1919. 
del sindicato ebanista, quedando en pie y reforzándose el momento de "centralización". En otras palabras, lugares de trabajo desorganizados, por un lado, y una dirección sindical cada vez más aislada de las luchas cotidianas entre capital y trabajo, por el otro.

Si tuviéramos que aventurar una hipótesis, podría afirmarse que las consecuencias de esta tendencia hacia la centralización "administrativa" que comenzaron a asumir algunos sindicatos en particular (ferroviarios, ebanistas, gráficos, marítimos) se puso de relieve en una fase de retracción de las luchas obreras y, en términos generales, de reflujo de la lucha de clases mediante un reforzamiento del aparato represivo del Estado. En este punto, el declive de la actividad huelguistica cristalizó aquel pragmatismo negociador propio del sindicalismo que, si habia crecido durante el auge de la lucha, en momentos de "quietud" se volvía una correa de supervivencia para este sector político.

Durante estos años, los sindicalistas profundizaron la tendencia a localizar en algún nivel del aparato del Estado una posición de mediación, sea con la policía, sea con el Ministerio del Interior, sea con el propio presidente, como haría en 1927 Alejandro Silvetti para que liberaran al organizador de los mensúes, Eusebio Mañasco. ${ }^{31}$ Desde esta perspectiva de paulatina integración "sistémica" a través de un diálogo en momentos de conflicto, puede comprenderse mejor la defensa de la ley de asociaciones gremiales que le brindaba "personería jurídica" a los sindicatos, en septiembre de 1926. En un artículo, Juan Pallas defendía la ley como la cristalización de una conquista obrera previa, al igual que habia sucedido, por ejemplo, con la jornada de 8 horas ya que "aquello que el Estado no legaliza, lo destruye". ${ }^{32}$ No todos apoyaron abiertamente este paso, entre otros, Silvetti. La defensa de la llamada "capacidad civil" o "jurídica" del organismo sindical se debatió en la asamblea mueblera del 7 de octubre de 1927; a medianoche, 97 votaron a favor de "ver con simpatía todo lo que tiene de bueno la ley" contra 145 que indicaron "que se combata categóricamente". ${ }^{33}$

Desde una perspectiva similar pueden comprenderse los debates en ocasión del proyecto de ley 11.289 sobre las jubilaciones, impulsado por el gobierno de Alvear en mayo de 1924 (Horowitz, 2015). Esto motivó la declaración de la huelga general por parte de todas las centrales sindicales en virtud de que conminaba a los trabajadores a ver rebajados sus salarios en favor de una caja previsional bajo el dominio del Esta-

31. Para profundizar en la aproximación del sindicalismo hacia las leyes laborales, ver en el presente dossier el artículo de Laura Caruso.

32. "La ley sobre asociaciones gremiales", Acción Obrera, n 27, octubre de 1926.

33. "La asamblea del día 7 del actual", Acción Obrera, n 36, octubre de 1927. 
do. ${ }^{34}$ En la medida en que las entidades empresarias también sumaron su rechazo, la ley fue finalmente suspendida. Sin embargo, si bien la huelga se dio en un marco de intervención común, el cierre fue visto como prematuro desde varios sectores. Los sindicalistas destacaban que "De aplicarse la ley, serán los patrones quienes tendrán que hacer por su cuenta los aportes que antes de la huelga correspondian a los trabajadores. En este caso la jubilación ya tiene un carácter distinto al de su origen: dejó de ser la exacción a los salarios para convertirse en una conquista de la clase trabajadora". ${ }^{35}$ Desde la mirada comunista, la dirección sindicalista de la USA se aprestaba a acompañar de forma silenciosa el proyecto de las jubilaciones. ${ }^{36}$ En la misma dirección se expresaba el sindicalista rojo Aurelio Hernández, sosteniendo que la USA habia "traicionado" la huelga desde el comienzo. ${ }^{37}$ En coincidencia con el PC, Hernández acusaba a la central de buscar la "reforma" de la ley.

Luego de la huelga general contra la "ley-trampa" (como se la conoció en la época), el sector sindicalista "autonomista", encabezado por el ebanista Silvetti, decidió presentar su renuncia al frente del Comité Central (CC) de la USA. En este punto, una posibilidad es que el grupo saliente hubiera suscripto una suerte de "pacto" con los militantes de la Alianza Libertaria Argentina (ALA), quienes de esta forma se hicieron con el mando de la central a mediados de diciembre de 1924, a través de una elección vía referéndum donde votaron 20.431 afiliados (Marotta, 1970)..$^{38}$ Como lo prueba la nómina del CC de la USA, los puestos clave de secretario general y tesorero pertenecian a militantes de esta corriente: secretario general, Sebastián Ferrer; tesorero, Atilio Biondi. Asimismo, es de destacar que, entre los 23 vocales del CC, el peso de los sindicalistas seguía siendo determinante y, además, nueve pertenecian al sindicato ebanista: Hernández y Mársico sindicalistas rojos; Cuomo, Silvetti, Daverio e Ibañez, "autonomistas"; Nejamis, Pérez y Sánchez, comunistas.

En líneas generales, podría hipotetizarse que tanto la ley de jubilaciones de 1924 como los proyectos para darle personería jurídica a los sindicatos en 1926 fueron intentos "desde arriba" por incorporar personal al aparato estatal, proveniente de las filas de los trabajadores. Así, la combinación de un momento de alta centralización de las decisiones (mando sindical) con el acercamiento cada vez mayor hacia

34. "La huelga general proletaria paraliza totalmente la Capital Federal", La Internacional, 6 de mayo de 1924.

35. "Más allá de la ley", Acción Obrera, n 3, junio de 1924.

36. "La USA y el poder ejecutivo", La Internacional, 6 de mayo de 1924.

37. "La última huelga general", Acción Obrera, n³ 3, junio de 1924.

38. Para un análisis sobre la corriente ALA, véase Doeswijk (2013: 243-287). 
la esfera estatal (o, por lo menos, la prevalencia de una orientación en un sentido "estatalista", de búsqueda por negociar "desde arriba") le dio un rasgo peculiar a la corriente sindicalista en la Argentina. ¿Cuál era la naturaleza de esta peculiaridad? A nuestro entender, la combinación resultante entre, por un lado, la búsqueda por afianzar al movimiento sindical como un interlocutor "válido" frente al Estado moderno (capacidad de negociación) y, por el otro (y en esto radica el déficit principal de la mayoria de los análisis), la trayectoria previa de lucha y organización del movimiento obrero argentino y el rol central que jugó el sindicalismo en esa etapa, generando nuevas formas organizativas a través de una militancia gremial de características originales en el país. Con ella, la reputación y autoridad que conquistaron ciertos cuadros sindicales entre los trabajadores. Este último aspecto debiera jerarquizarse como el punto de partida ineludible de nuevos estudios, iluminando un costado muchas veces omitido por la historiografia.

\section{Conclusiones}

A través de este artículo, nos propusimos analizar la trayectoria de la corriente sindicalista y sus formas de organización en la industria maderera. Así, examinamos la íntima relación entre el aumento o la disminución del empleo, la "autonomía artesanal" derivada de la configuración del proceso de trabajo y la extensión o atrofia de la organización sindical. Cabe destacar que, si bien la disminución del trabajo era un factor desfavorable al igual que en cualquier otra rama, no es menos cierto que la exigencia propia del oficio mueblero imposibilitaba la contratación de obreros sin capacitación. En este punto, afirmamos que una de las premisas centrales de la acción sindicalista fue dicha autonomía artesanal, cristalizada en resortes de contralor obrero como la tarjeta sindical o el label, que se sostenían sobre un sistema de delegados por taller. Así, el sindicalismo revolucionario descolló en un gremio de alta calificación como eran los ebanistas y el anarquismo mantuvo una centralidad entre los carpinteros, cuya calificación era menor.

En segundo lugar, los sindicalistas afianzaron su dominio a través de luchas parciales y en torno a mejoras inmediatas sobre las condiciones laborales. En los momentos clave, observamos también el alto grado de centralización de las decisiones desde la conducción sindical; circunstancia que luego derivó en una virtual separación de la dirección del resto del cuerpo gremial. De este modo, es factible delinear el contexto dentro del cual se verificaron los debates entre sindicalistas "rojos" y "autonomistas", de importancia entre el gremio maderero.

Por último, es factible aseverar que los rasgos descriptos como parte de la fisonomía del sindicalismo en la industria de la madera trascen- 
dieron el caso del sector del mueble para constituirse en características permanentes del sindicalismo revolucionario, que se plasmaron en los distintos intentos por estructurar una central obrera nacional. En pos de completar este objetivo estratégico, no fue menor la contribución del gremio maderero, un verdadero "laboratorio" a escala reducida de los planteos teóricos y prácticos del sindicalismo criollo.

\section{Bibliografia}

Aquino, Cristian (2015), "Bajo la influencia de la Revolución Rusa. La Federación de Agrupaciones Sindicalistas Revolucionarias a través de La Batalla Sindicalista, 1920-1923", Archivos, año IV, n ${ }^{\circ} 7$, septiembre, Buenos Aires, pp. 123-142.

Bilsky, Edgardo (2011), La Semana Trágica [1984], Buenos Aires: Razón y Revolución.

Camarero, Hernán (2007), A la conquista de la clase obrera. Los comunistas y el mundo del trabajo en la Argentina, 1920-1935, Buenos Aires: Siglo XXI Iberoamericana.

- y Diego Ceruso (2015), "Una historia del sindicato de la madera: organización gremial e influencia de la izquierda en las luchas obreras, Buenos Aires, 1917-1943", el@tina. Revista electrónica de estudios latinoamericanos, vol. $13, \mathrm{n}^{\circ} 50$.

Camarero, Hernán y Carlos Herrera (2005), El Partido Socialista en Argentina. Sociedad, politica e ideas a través de un siglo, Buenos Aires: Prometeo.

Caruso, Laura (2016), Embarcados. Los trabajadores maritimos y la vida a bordo: sindicato, empresas y Estado en el puerto de Buenos Aires, 18891921, Buenos Aires: Colección Archivos, Imago Mundi.

Ceruso, Diego (2015), La izquierda en la fábrica. La militancia obrera industrial en el lugar de trabajo, 1916-1943, Buenos Aires: Colección Archivos, Imago Mundi.

Del Campo, Hugo (1983), Sindicalismo y peronismo, Buenos Aires: Clacso.

Doeswijk, Andreas (2013), Los anarco-bolcheviques rioplatenses (1917-1930), Buenos Aires: Cedinci.

Falcón, Ricardo (1987), "Izquierdas, régimen político, cuestión étnica y cuestión social (1890-1912)", Anuario Escuela de Historia, n 12, Rosario.

Horowitz, Joel (2015), El radicalismo y el movimiento popular (1916-1930), Buenos Aires: Edhasa.

Lobato, Mirta Zaida (2000), "Los trabajadores en la era del progreso", en AA. VV., Nueva historia argentina, Buenos aires: Sudamericana.

Marotta, Sebastián (1961), El movimiento sindical argentino. Su génesis y desarrollo, tomo II: Periodo 1907-1920. Buenos Aires: Lacio.

- (1970), El movimiento sindical argentino. Su génesis y desarrollo, tomo III: Periodo 1920-1935, Buenos Aires: Lacio. 
Montgomery, David (1979), Workers' control in America: studies in the history of work, technology, and labor struggles, Cambridge University Press.

Poy, Lucas (2014), Los origenes de la clase obrera argentina. Huelgas, sociedades de resistencia y militancia politica en Buenos Aires, 1888-1896, Buenos Aires: Colección Archivos, Imago Mundi.

Suriano, Juan (2001), Anarquistas. Cultura y politica libertaria en Buenos Aires, 1890-1910, Buenos Aires: Manantial.

Tilly, Charles (1995), Popular Contention in Great Britain, 1758-1834, Cambridge: Harvard University Press.

Troncoso, Oscar (1983), Fundadores del gremialismo obrero, tomo II, Buenos Aires: CEAL.

$$
* * *
$$

Titulo: A political-trade union laboratory: revolutionary syndicalism in the wood industry

Resumen: En este artículo se reflexiona sobre la intervención del sindicalismo revolucionario en el gremio maderero de la ciudad de Buenos Aires durante el período 1915-1930. A partir del estudio de caso, se analizan las prácticas militantes y las formas organizativas dentro de un sector con alta calificación y escaso desarrollo productivo. Se sostiene que la intervención del sindicalismo entre estos trabajadores permitió apuntalar la acción política en el terreno de las centrales obreras nacionales; desarrollar formas de aproximación hacia el Estado en momentos clave (ley de jubilaciones de 1924 y de personeria jurídica en 1926); así como también desenvolver un proceso de diferenciación interna dentro de la corriente. Mediante el relevamiento de fuentes primarias, centralmente prensa, se plantea una mirada renovada sobre la trayectoria del sindicalismo local.

Palabras clave: sindicalismo revolucionario - gremio maderero - prácticas militantes - formas organizativas

Abstract: In this paper we consider the role of revolutionary union tendency in shaping the woodworkers' union in Buenos Aires between 1915-1930. Based on this case study, we aim to analyze activist's practices and forms of organization within a highly qualified sector whose productivity is also scarcely developed. We argue that the sustained intervention of unionism among these workers made political action possible in the domain of national worker unions. It also allowed to develop different ways of closeness to the State in pivotal moments (Retirement Act, 1924; Legal Status Act, 1926) and develop a process of internal differentiation within the current. A renewed look about native unionism is outlined by means of the survey of primary sources.

Keywords: revolutionary unionism - woodworker's union - activist's practices - forms or organization

Recepción: 23 de diciembre de 2016. Aprobación: 2 de febrero de 2017. 